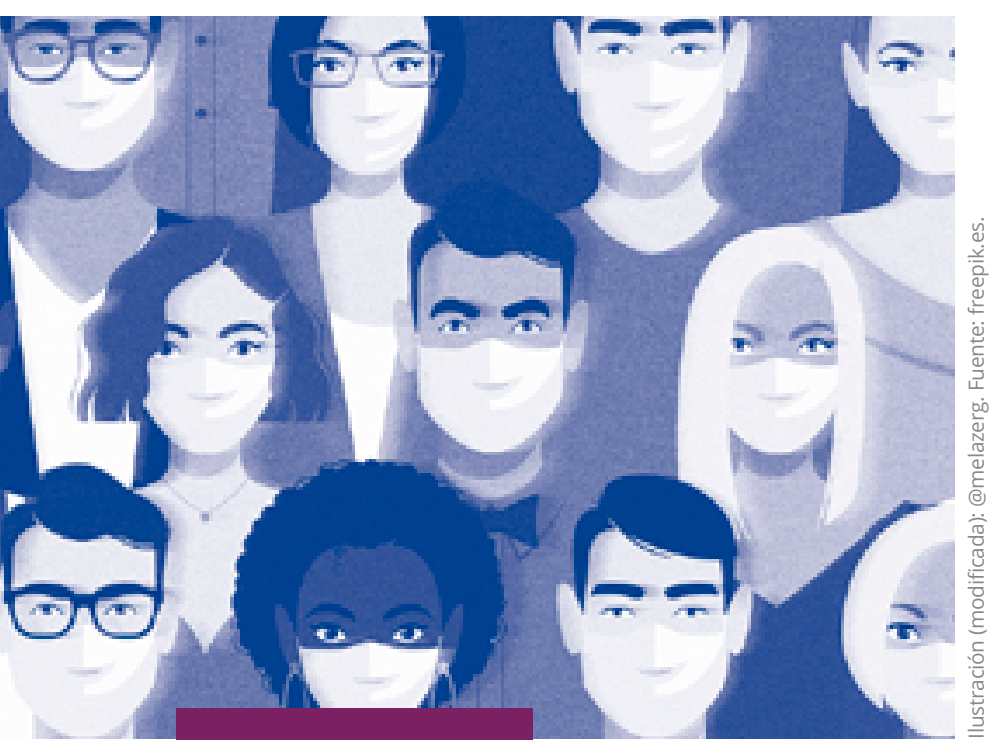

FIGURAS REVISTA ACADÉMICA DE INVESTIGACIÓN ISSN 2683-2917

Vol. 2, núm. 2, marzo-junio 2021

https://doi.org/10.22201/fesa.figuras.2021.2.2

Esta obra está bajo una licencia

Creative Commons Atribución-NoComercial-

Compartirlgual 4.0 Internacional

\section{Covid-19: parteaguas para el Orden Mundial del siglo XXI}

\author{
Covid-19: a Turning Point for the World \\ Order in the 21st Century \\ https://doi.org/10.22201/fesa.figuras.2021.2.2.154
}

Isaías G. Noguez-Tinoco

Secretaría de Relaciones Exteriores. Servicio Exterior Mexicano

Se trata del primer compendio que revisa, desde una perspectiva multidisciplinaria, el impacto de la pandemia de covid-19 en las relaciones internacionales. Se integra de colaboraciones especializadas en materia de geopolítica, economía y salud. Un libro para reflexionar sobre la crisis sanitaria, sus efectos y los desafíos que traerá para la forma de gobernar mundial en el siglo XXI.

\section{Covid-19: parteaguas}

La Organización Mundial de la Salud (OMS) declaró el 11 de marzo de 2020 que el coronavirus SARS-CoV-2 (covid-19 en lo sucesivo para fines de esta reseña) era considerado a partir de esa fecha como pandemia mundial debido a los niveles de propagación, contagio y defunciones alcanzados en alrededor de 115 países, cuatro meses después de que se tuviera registro oficial del primer caso detectado en la ciudad de $\mathrm{Wu}$ han, China.

Durante la conferencia de prensa en la que se llevó a cabo ese anuncio, Tedros Adhanom, director general de la oms, hacía un llamado a la comunidad internacional a tomar medidas urgentes para cambiar el curso y los efectos que podría tener la pandemia: "es una crisis que afectará a todos, por lo que cada persona debe participar en la lucha". Se trató de una alerta que de manera inesperada irrumpiría en todos los rincones del mundo, sin distinción alguna.

Por la dimensión y los alcances que ha tenido la covid-19 y los efectos que traerá consigo para los próximos años, es muy posible que se trate de un parteaguas y punto de referencia en el análisis de la historia de la humanidad del siglo xxI. Una crisis sanitaria que marcará el rumbo de la política, la economía, la vida pública y las relaciones internacionales en una sociedad que ya convulsionaba y cuestionaba las condiciones y fórmulas del statu quo del orden mundial liberal.

¿Qué elementos explican en su conjunto la crisis que desató de manera global la covid-19? ¿Cuáles son las lecciones que deja el manejo de la emergencia política, social y económica que derivó de esta pandemia? ¿Cuál es el camino que se debe construir y las oportunidades que se pueden aprovechar a partir de la covid-19?

Gian Luca Gardini, profesor de la Universidad Friedrich-Alexander de Erlangen-Nuremberg (FAU), se dio a la tarea de coordinar el primer ejercicio analítico que revisa, desde una perspectiva multidisciplinaria, 
el impacto de esta pandemia en las relaciones internacionales. El mundo antes y después del covid-19. Reflexiones intelectuales sobre la política, la diplomacia y las relaciones internacionales es un libro disponible en español e inglés que se integra de 30 artículos, preparados por 35 reconocidos especialistas en sus respectivas disciplinas, que busca plantear las condiciones para el diálogo y reflexión de las causas, desafíos y retos que la pandemia ha traído consigo, así como algunos apuntes sobre sus consecuencias y posibles hojas de ruta que se podrían diseñar a partir de la misma.

Para ello, y aprovechando su posición como titular de la Cátedra de Negocios Internacionales y Relaciones Sociales de la FAU, Gardini presenta esta obra elaborada conjuntamente con el Instituto de Estudios Internacionales, un destacado y reconocido centro de investigación y educación con sedes de trabajo en España y Suecia, en temas de diplomacia, gobernanza global, crecimiento económico y desarrollo sostenible. La vocación de ambas entidades da sentido al marcado interés por presentar este ambicioso proyecto que busca abarcar a la covid-19 como objeto de análisis desde una óptica multidimensional y propositiva.

La obra se compone de cuatro secciones que abordan a la covid-19, por una parte, desde un marco de referencia temático, pasando por aspectos que impactan de manera general en la política, la economía y la medicina; y por otra, desde una perspectiva testimonial de casos en diferentes países y bloques regionales en el mundo. Es importante destacar que la edición del libro fue concluida a finales de mayo de 2020 , por lo que las disertaciones presentadas incluyen los hechos y elementos que se tenían presentes hasta esa fecha.

En cuanto a los aspectos más relevantes que la pandemia ha traído para las relaciones internacionales, la diplomacia y el orden mundial, las dos primeras secciones del libro abordan reflexiones sobre la geopolítica, la economía y la cooperación internacional, así como sobre las herramientas y espacios de concertación mundial de nuestros días. Hay una revisión crítica de las condiciones que provocaron una reacción poco eficaz y lenta ante la covid-19, en la que la crisis de credibilidad que afrontan el multilateralismo y la democracia como motores del desarrollo y progreso son comunes denominadores. A su vez, la aparición cada vez mayor de regímenes con carácter populista y nacionalista son otro síntoma que explica la falta de rumbo coordinado como respuesta a la emergencia desatada por la pandemia.

\section{EL MUNDO ANTES Y DESPUÉS DEL COVID-19}
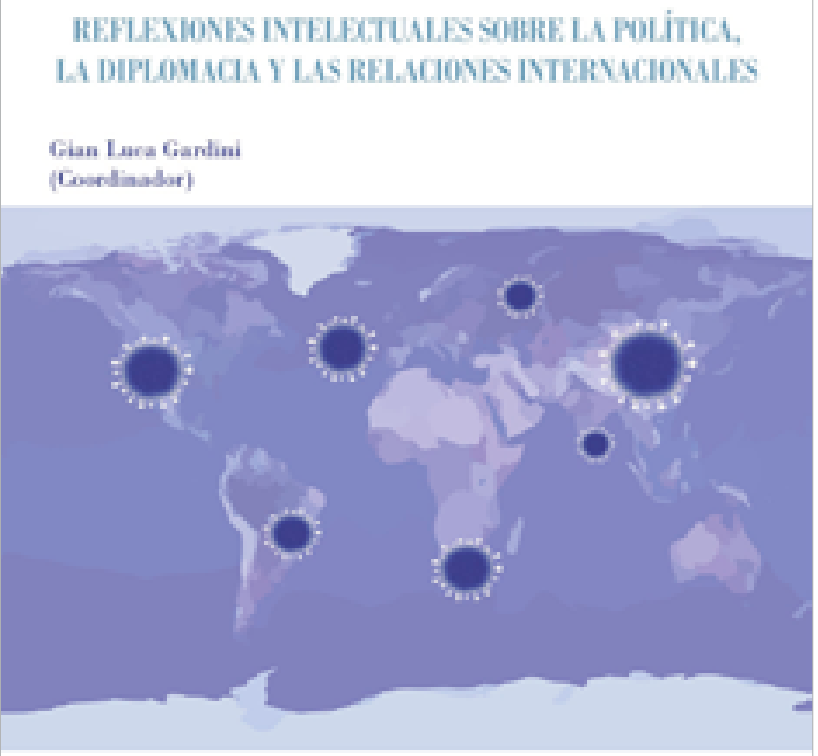

Eus

Portada del libro El mundo antes y después del COVID-19. Reflexiones intelectuales sobre la política, la diplomacia $y$ las relaciones internacionales.

Las confrontaciones ideológicas y políticas y los cuestionamientos al orden global liberal, que no se originaron por la covid-19, sí exacerbaron las diferencias, hicieron más evidentes las desigualdades y los intereses nacionales. Por otra parte, también se 
deja registro de que, ante la incertidumbre y miedo ocasionados por la pandemia, se hicieron patentes valores como la solidaridad y la responsabilidad individual, así como la reflexión sobre la relación del ser humano con su entorno.

Los diferentes especialistas participantes en este libro reconocen que el papel del Estado nacional se ha visto fortalecido como principal actor después de décadas en las que se cuestionaba su papel en el mercado y la dinámica internacional. La ciudadanía en general ha tenido que depositar la confianza en sus respectivos gobiernos para seguir las disposiciones y protocolos que fueran necesarios para reducir la amenaza: ya fuera el establecimiento de estrictos confinamientos sociales, la parálisis de la vida económica o la atención sanitaria centralizada en los momentos más críticos de contagios.

No obstante, se destaca que al mismo tiempo la crisis por la covid-19 ha dejado claro que la seguridad y amenazas para la humanidad están relacionadas e interconectadas, en lo individual y en lo colectivo, en un mundo interdependiente que requiere acciones colectivas y universales para garantizar su subsistencia. Las estrategias y planes que se desarrollen deben de tener a la gestión política, la cooperación y la diplomacia como pilares para hacer frente a los problemas como esta pandemia, el cambio climático o la pobreza. "El virus es uno y muchos al mismo tiempo. El mundo es uno y muchos al mismo tiempo también", señala Gardini.

La nueva forma de ejercer el gobierno mundial y el renovado enfoque de las relaciones internacionales que se deben establecer a partir de la covid-19 deben tener presente, de acuerdo con lo señalado por los especialistas, una reformulación en todas sus estructuras y marcos conceptuales para contar con mejores políticas y herramientas para hacer frente y responder de mejor forma a las amenazas futuras. El sistema productivo, el comercio y la arquitectura financiera internacional no deben enfocarse solamente en ser eficientes, productivos y buscar su reactivación in- mediata, sino también en ser solidarios, sustentables y con conciencia social, así como también deben tener a la educación y a las nuevas tecnologías como medios y herramientas fundamentales.

Con esta aspiración, ¿qué aspectos positivos y qué errores deja para el análisis el manejo de la crisis por covid-19? Gardini presenta en la tercera sección de este libro un comprensivo compendio de experiencias y casos particulares en lo nacional, así como a nivel regional. Se revisa el impacto que la pandemia ha traído para Estados Unidos y para China, los efectos de las medidas que cada país ha adoptado en el manejo de la emergencia y las repercusiones que irremediablemente han generado como referentes mundiales. Para ambos casos se reconoce que la pandemia vino a ser un catalizador de los desafíos que cada nación afrontaba al interior, sus modelos de desarrollo y su relación con la comunidad internacional.

Asimismo, se presentan aspectos particulares de países como España, Italia y Alemania en su respuesta inicial a la crisis sanitaria y la preparación para lo que en ese entonces se denominó "nueva normalidad" dentro del marco de convivencia europeo. De igual forma, se destacan los casos de Corea del Sur y de Brasil como dos de las naciones más afectadas por la pandemia y las acciones que cada una de ellas llevó a cabo para hacerle frente. Sobre Corea del Sur se destacan las principales estrategias que la llevaron a ser considerada en ese momento como modelo de respuesta ante la covid-19. Para Brasil, se presenta una semblanza de la situación que ya enfrentaba el país con el actual gobierno y los posibles efectos que se afrontarán como resultado del manejo de la crisis sanitaria.

En el plano regional se da una revisión general a los principales desafíos que la Unión Europea ha confrontado en su conjunto para gestionar la crisis sanitaria y se deja constancia de las diversas acciones realizadas por el grupo de 27 países que la integran y que se consideran significativas para mitigar de manera compartida los efectos frente a la pandemia. Para el caso de América Latina, se señalan los problemas 
estructurales que la covid-19 ha dejado de manifiesto para la región y que, desafortunadamente, se prevé acentuarán la desigualdad y la falta de desarrollo.

La cuarta y última sección del libro tiene como finalidad mostrar elementos sobre las repercusiones y efectos que la pandemia ha traído desde la perspectiva médica, sanitaria y psicológica. En una obra editada desde la óptica de la política y las ciencias sociales, resulta relevante la presentación de este apartado debido al impacto que esta crisis ha traído en estas materias que son fundamentales de revisar, no solo por la naturaleza y origen sanitario del problema abordado, sino como parte integral de la respuesta y políticas públicas que se deben elaborar. La covid-19 es, desde el punto de vista de Gardini y los diversos especialistas que participan en esta obra, un punto de inflexión para analizar la realidad desde una perspectiva holística, multifacética y plural donde la política debe tener el rol principal para reorganizar la manera de ejercer el gobierno mundial, sin dejar de tener el enfoque en el bienestar integral del ser humano y la sociedad.

Bien se advierte que esta obra no busca brindar soluciones o respuestas definitivas en un tema tan complejo y aún en desarrollo como lo es la crisis por la covid-19 y sus múltiples consecuencias, pero sí se trata de una significativa contribución a la revisión, debate y discusión inicial de aspectos para tener en cuenta en los diversos planes o estrategias ante futuras pandemias y la re-configuración del orden mundial poscovid-19.

Uno de los objetivos que se plantea con este trabajo es impulsar un debate exhaustivo en el que se utilice un enfoque multidisciplinario y diverso con aportaciones en variadas temáticas y regiones. Y es en esta parte que se lamenta, por ejemplo, que no se haya buscado presentar la realidad de la pandemia en África, segundo continente más poblado en el mundo, que, si bien tardó en registrar una situación crítica comparado con Europa, ya tenía para mayo una situación que preocupaba. De igual manera, no hay mención de la gestión de la crisis realizada en Oceanía o Nueva Zelanda, que es, sin duda, uno de los casos más destacados a nivel mundial por el manejo efectivo de la situación bajo el liderazgo de la primera ministra Jacinda Ardern.

Al margen de lo anterior, se trata de un libro que puede resultar muy útil y de interés para toda persona lectora especializada o no en estas materias que busque analizar, cuestionar y comprender, con perspectiva de miras, el fenómeno de propagación mundial en el que se convirtió la covid-19 y reflexionar sobre posibles escenarios futuros que se pueden afrontar, a partir de esta coyuntura, en la arena internacional.

Finalmente, se considera que es una obra que abre la puerta para el desarrollo de investigaciones más profundas en disciplinas de estudio como la geopolítica y la prospectiva en las relaciones internacionales con miras a diseñar e implementar renovadas estrategias y acciones que ayuden a encontrar soluciones justas, sostenibles y de gran alcance para la gobernanza mundial del siglo XXI. -

Referencia

Gardini, Gian Luca, coord. 2020. El mundo antes $y$ después del COVID-19. Reflexiones intelectuales sobre la política, la diplomacia y las relaciones internacionales. Salamanca, Estocolmo: Instituto Europeo de Estudios Internacionales. https://www.ieeiweb.eu/wpcontent/uploads/2020/06/Full_book_FINAL_ESP2.0UNIDO.pdf 